\title{
Estratégias de proteção da face no cenário jurídico: um estudo de caso
}

\section{Carolina Scali Abritta}

Professora Adjunta da Universidade do Estado do Rio de Janeiro (UERJ), Brasil. carolabritta3o@gmail.com

\section{Sonia Bittencourt Silveira}

Professora Associada da Universidade Federal de Juiz de Fora (UFJF), Brasil. soniasilveira46@gmail.com

\section{Kricia Helena Barreto}

Professora Adjunta da Universidade do Estado do Rio de Janeiro (UERJ), Brasil. kriciabarreto_@hotmail.com

Resumo: Neste artigo, buscam-se descrever e analisar as estratégias discursivoargumentativas orais empregadas por ministros da mais alta Corte brasileira no trabalho interacional de proteger suas próprias faces numa audiência pública de julgamento, transmitida pela televisão no canal específico da Justiça brasileira. Os dados de fala-eminteração foram gravados e transcritos em conformidade com o modelo de Jefferson (LODER, 2008). A partir do estudo de caso desenvolvido pelas autoras, os resultados encontrados apontaram para um movimento fundamental, qual seja, de salvar a própria face apoiado, principalmente, nas ações de dizer coisas positivas sobre o self e dizer coisas negativas sobre o outro.

Palavras-chave: Trabalho de face. Estratégias discursivas. Corte. Conflito.

Abstract: This paper aims at studying the spoken discursive-argumentative strategies of face protection used by Brazilian high court Ministers in a public audience, broadcast by Brazilian justice TV channel. The data were recorded and transcribed (Jefferson, 1994) and the results point to the tendency of saving the face of the self through saying positive things about the self and negative things about the other.

Keywords: Facework. Discursive strategies. Court. Conflict. 
Introdução

Um dos grandes mestres da sociologia, o alemão Georg Simmel, já no início do século passado ${ }^{1}$, notava que as pessoas, uma vez postas em situação de interação, precisam usar do tato umas com as outras. Reforçava com isso um pressuposto de sua teoria: o de que o conflito integra e constitui as relações sociais. Simmel (2011 [1964]) defendia que o conflito inclusive é o que possibilita a mudança social, já que ela só viria após uma resolução dessa situação de tensão em que estamos permanentemente postos. Nesse sentido, para ele, assim como para nós, o conflito não deve ser visto, necessariamente ou aprioristicamente, como algo negativo, mas como fator inerente a qualquer relação inter-humana.

Goffman, alguns anos depois (1972 [1967]), nessa mesma linha, falará sobre os relacionamentos humanos nas interações. Prevê, primeiro, então, a precariedade dessas relações, já que reconhece o risco constante do embaraço nas situações face a face. $E$, ao analisar os rituais interacionais, vai assumir que todos envolvem algum tipo daquilo que chamou de trabalhos de face (1972 [1967]). Nesse sentido, para o autor, em situação de interação, podemos fazer uso de recursos discursivos que visem a manter ou mesmo ameaçar a maneira como buscamos ser reconhecidos uns pelos outros ao refutar ou sustentar as faces por nós reivindicadas. Goffman, embora preveja a ameaça à face, sempre faz lembrar que a preocupação com os desejos de face do self e do outro é condição das interações sociais.

Nas interações jurídicas, reconhecidas, já no senso comum, como conflituosas por excelência, temos um ambiente rico para estudar a maneira como os conflitos são aumentados ou mitigados, especialmente, olhando para os trabalhos de face desempenhados pelos interagentes.

Neste artigo, temos como foco de análise olhar para a maneira como alguns ministros da mais alta Corte brasileira constroem conjuntamente o trabalho de proteger suas próprias faces numa audiência pública de julgamento. Essa audiência ganhou grande repercussão, nos mais diversos meios de imprensa nacional, devido ao alto grau de conflito presente na fala dos interagentes. Por sua riqueza e especificidade, os dados aqui analisados já foram alvo de análises anteriores (SILVEIRA; ABRITTA, 2015) tendo como

\footnotetext{
${ }^{1} \mathrm{O}$ texto usado aqui é tradução de 2006 do livro Questões fundamentais da Sociologia, feita a partir da edição alemã de 1999. O original da obra, entretanto, foi primeiramente publicado em 1917.
} 
enfoque, entretanto, as estratégias discursivo-interacionais de ataque à face empregadas pelos ministros.

Aqui, tal como lá, oferecemos uma análise de caso, sem pretensões generalizantes, mas com intenções de aprofundar e ampliar a discussão sobre o dinâmico processo da co-construção da face no ambiente, muitas vezes belicoso, das interações sociais. Para tanto, iniciaremos apresentando de maneira mais detalhada os conceitos e trabalhos de face em Goffman (1972 [1967]), as revisitas feitas ao conceito de face e, secundariamente, ao tratamento dado às estratégias de trabalho de face por teorias interacionais mais recentes, e, por fim, a maneira como nós os vimos emergir na interação da Corte que elegemos para analisar.

\section{O conceito de face segundo Goffman}

Torna-se relevante, para este trabalho, revisitarmos o conceito de face, introduzido nos estudos sociais pelo sociólogo Erving Goffman, e sua relevância nas interações ocorridas no cenário jurídico. Segundo Goffman (1972 [1967]), as pessoas interagem para apresentar uma personalidade, obter conhecimento dos outros, e para aumentar a imagem do self ${ }^{2}$ e/ou do outro para si mesmas ou para outros.

A noção de self, para Goffman, no trabalho citado, é de um construto de natureza pública já que emerge na interação. É no processo interacional que o self é criado e manipulado. As pessoas apresentam seus selves de determinadas maneiras e, na interação, as definições do self são mantidas e reforçadas. Isso é o que Goffman chama de trabalho de face, definido como "as ações realizadas por uma pessoa para tornar o que quer que esteja fazendo consistente com a face" (1972 [1967], p. 5). A face é, por sua vez, o "valor social positivo que uma pessoa efetivamente reclama para si mesma através daquilo que os outros presumem ser a linha por ela tomada durante um contato específico" (1980 [1955], p. 76-77), sendo a linha o "padrão de atos verbais através dos quais o indivíduo expressa sua visão da situação e, através disso, sua avaliação dos participantes, especialmente de si mesma" (p. 76).

\footnotetext{
${ }^{2}$ Harré e Gillet ([1994] 1999), ao conceituar discursivamente o termo self, definem que essa noção "não possui a implicação cartesiana de referência a uma entidade interna" e assumem a impossibilidade de tradução do termo ao dizerem: "não é obvio que equivalentes para esta palavra possam ser encontrados e usados de forma estreitamente similar em outras línguas" (p. 90). Por essas razões, mantivemos o termo em inglês, bem como o plural que lhe é correspondente selves.

${ }^{3}$ Optamos por transpor para este texto o conceito conforme traduzido na bibliografia de 1980, clássica para os estudos de face no Brasil.
} 
Em seu influente trabalho "Ritual de Interação" (1972 [1967]), Goffman expande o conceito de linha e a define em termos de ação simbólica, ritualizada (p. 4). A face reflete a linha atribuída por outros ao ator, com base no uso de símbolos verbais e não-verbais, seja afirmando ou negando um construto social. As pessoas apresentam uma linha, uma face, e esta face, ainda que seja irreal, deve sempre ser consistente com a linha adotada em um dado momento da interação. Desse modo, o self pode ser definido como "o código que dá sentido a quase todas as atividades do indivíduo e fornece uma base para organizá-las" (GOFFMAN, 1971, p. 366).

Nos encontros sociais, as questões de face envolvem a responsabilidade de todos os participantes, a "face nunca é algo puramente individual" (HO, 1976, p. 882). Goffman afirma que face é um construto social, é apenas um empréstimo feito pela sociedade ao indivíduo: caso ele não se comporte de modo a merecê-la, sua face poderá ser-lhe retirada. Assim, "questões de face emergem não em processos privados de avaliação do self, mas nos encontros sociais em que as nossas avaliações pelos outros são percebidas como relevantes para a manutenção das posições na sociedade"4 (HO, op. cit., p. 875, tradução nossa).

\subsection{Face e as interações sociais: um retorno à obra de Goffman}

$\mathrm{Na}$ literatura sobre estudos da face, muitos autores revisitam o conceito de Goffman (1972 [1967]) com vistas a criticá-lo e/ou a reformulá-lo. Arundale (2006, 2010), por exemplo, afirma que a noção de (trabalho de) face de Goffman, calcada na psicologia social, focaliza o indivíduo como unidade de análise (e não a díade interacionalmente alcançada), e problematiza a ideia de que face, para Goffman, liga-se aos desejos individuais que movem a ação humana. De fato, como nos lembra Bargiela-Chiappini (2003), o ator social de Goffman possui uma preocupação quase obsessiva com sua autoimagem e autopreservação. Porém, essa mesma autora nos lembra de que a conceitualização de trabalho de face em Goffman (1972 [1967]) relaciona-se com a apresentação do self em encontros sociais, ou seja essa apresentação está sujeita à ordem interacional que sustenta a interação social em curso e à qual todos os indivíduos/participantes estão sujeitos. Assim, a eminente

\footnotetext{
${ }^{4}$ No original: "Questions of face arise, not in the private process of self-evaluation, but in social encounters where the evaluations by others of oneself are perceived to be of significance to the maintenance of one's standing in society."
} 
linguista reconhece que embora a psicologia individual seja relevante, é a ordem interacional que é o foco dos estudos de Goffman.

De todo modo, grande parte da crítica que se faz à noção de face diz respeito primordialmente à interpretação seletiva dada por Brown e Levinson (1987 [1978]) para o conceito de Goffman, uma interpretação

\begin{abstract}
"inequivocadamente, em termos individualistas, abstraindo não apenas da dimensão da ordem ritual, mas de todos os tipos de ordem social" (Konrad Werkhofer, 1992, p. 178), privilegiando, assim, noções cognitivas implícitas no entendimento Griceano de comunicação sobre as noções de ordem social favorecidas por Goffman. ${ }^{5}$ (BARGIELA-CHIAPPINI, op. cit., p. 1455, tradução nossa).
\end{abstract}

Em seus estudos sobre polidez, Brown e Levinson criaram "a impressão de que face é um atributo a priori de indivíduos que podem ser ameaçados na interação, e que precisam, assim, acima de tudo, serem protegidos"6 (TERKOURAFI, 2007, p. 320). Como observa Bargiela-Chiappini (op. cit.), a conceituação de polidez positiva e negativa como duas instâncias mutuamente exclusivas não abre espaço para a coexistência de situações nas quais vários desejos de face são ameaçados simultaneamente. A presença de múltiplos trabalhos de face não é tratada, de forma sistemática, em suas estratégias de polidez e, conforme ressalta Haugh (2009), face é mais complexo do que a mera ameaça à autoimagem do indivíduo: ela pode envolver um cuidado com a posição de alguém dentro de uma rede de relações, ela pode ser associada tanto a grupos quanto a indivíduos, e face pode ser dada ou ganhada, assim como sacrificada, dentre outras coisas, e não simplesmente perdida ou salva.

Desse modo, neste trabalho, optamos por realizar um retorno ao conceito original de face e trabalho de face de Goffman, como proposto por Bargiela-Chiappini (op. cit.), e nos alinhamos, ainda, à discussão realizada por Haugh (op. cit.) no prefácio do livro Face, Communication and Social Interaction (2009), editado por Haugh e Bargiela-Chiappini, por acreditarmos que se tratem de pontos de vista complementares à visão do sociólogo. Haugh (op. cit.) defende que face deva ser compreendida como um conceito

\footnotetext{
${ }^{5}$ No original: "[In his historical study of politeness, Konrad Werkhofer (1992:178) laments the selective interpretation of Goffman's face metaphor in] "unambiguously individualistic terms, abstracting not only from the dimension of ritual order, but from all kinds of social order", thus privileging cognitive notions implicit in the Gricean understanding of communication over the social ones favored by Goffman."

${ }^{6}$ Tradução das autoras. No original: "The impression that face is an a priori attribute of individuals that stands to be threatened in interaction, and must thus above all be safeguarded."
} 
fundamentalmente interacional, visto que ela pressupõe avaliação de outros do comportamento dos indivíduos e de grupos. Face é, portanto, não apenas co-constituída na interação, mas constitutiva da interação (p. 12), uma vez que ela emerge através da interação como uma realização conjunta entre os interlocutores.

A implicação desse conceito para estudos de face encontra-se justamente na necessidade de se realizar análises etnometodológicas para a compreensão dos aspectos não-sequenciais da interação. Conforme Watson e Gastaldo (2015), a etnomedologia nos fornece ferramentas para o estudo dos métodos usados pelas pessoas comuns da sociedade para dar sentido às coisas do mundo (p. 13). Por meio dessa visão sociológica, que elege o cotidiano como objeto de investigação e o discurso como sua matéria-prima para promover essas pesquisas, pressupõe-se que as análises dos trabalhos de face deverão levar em conta não apenas aspectos situados, mas também as dimensões históricas e socioculturais da face e dos trabalhos de face (HAUGH, op. cit., p. 11).

\subsection{A face nas interações jurídicas}

Desde Brown e Levinson (1978), as teorias de polidez, que também abordam o fenômeno da construção de face em interações sociais, preveem que o conflito e os ataques à face, enquanto ações argumentativas, têm suas realizações vistas como esperadas em contextos forenses.

Leech (1983) dizia que, em contextos específicos, a preservação das faces parece ser uma meta comunicativa secundária, havendo então tipos de atividade em que a fala conflitiva seria constitutiva da interação.

Nem por isso, contudo, nesses contextos, teríamos um vale-tudo no que tange à questão dos ataques à face. Karen Tracy (2008) diz que há de haver uma razoabilidade na demonstração da hostilidade, sem a qual, ao que parece, os encontros sociais podem ir a termo. Nesse mesmo sentido, Bousfield (2008) e Archer (2008) assumem que, no contexto específico da Corte, embora haja a expectativa de que os advogados de acusação sejam até mesmo agressivos, há de ser evitado o emprego de ofensas consideradas gratuitas.

E a linguista, Sandra Harris, em um de seus últimos trabalhos (2011), ao falar sobre a polidez na Corte, advoga que o uso de expressões polidas possibilita a manutenção da "civilidade" e sinaliza que as ameaças às faces 
não devem ser tomadas como insultos ou ofensas pessoais. Harris (2011) corrobora ainda a ideia de que, apesar de relevantes na Corte, os trabalhos de face são, nesse ambiente, sempre uma meta secundária do evento, já que a meta principal seria elicitar, apresentar, avaliar as evidências envolvidas na discussão em curso.

Penman $(1990,1994)$ diverge dessa posição advogada por Leech (1983) e Harris (2011), qual seja, a de que pode haver contextos em que há primazia da informação sobre as questões relacionais. Penman, nos textos citados, e também Arundale (2006), sustentam a tese de que em paralelo à ordem informacional há o gerenciamento das relações interpessoais, não havendo uma hierarquia entre esses domínios da linguagem. Nesse sentido, Penman (1990) defende que, no contexto da Corte, há dois jogos de linguagem em curso, um jogo oficial da troca de informações e outro jogo subjacente de trabalhos de face, este último, em especial, tem demonstrado influir na possibilidade de resolução do conflito ou, ao contrário, no escalonamento do mesmo.

Penman (1990) ainda nos diz mais sobre a questão da especificidade das faces no contexto forense. Para ela, as estratégias de trabalho de face são organizadas em um continuum, a partir da dimensão respeito-desprezo pela face dos atores sociais. Respeito pode ser mostrado na forma de deferência ou admiração pelo outro; por outro lado, agir com dignidade, por exemplo, sinaliza respeito pelo self. O desprezo pelo outro pode ser manifesto através de desdém, depreciação. Já o desprezo pelo self pode ser indiciado por comportamentos que envolvem diferentes graus de autodepreciação. A dimensão respeito-desprezo pelo self ou pelo outro está na base de quatro macrocategorias de estratégias de trabalho de face, conforme esquema abaixo:

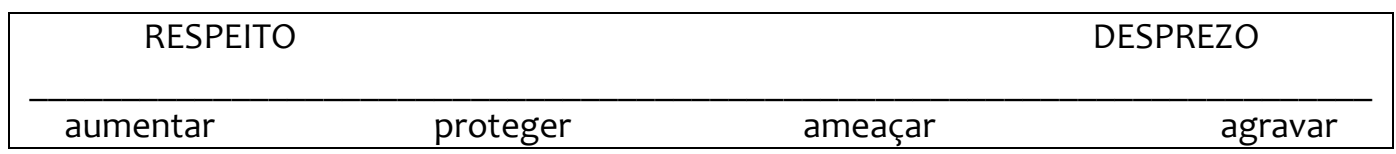

As estratégias de aumentar/proteger a face do self corresponderiam, em Goffman (1972 [1967]), aos movimentos de dar e salvar a face, e as estratégias de ameaçar/agravar, a movimentos de perda da face do self e/ou do outro e a defacement (caso extremo de agravamento, desrespeito aos desejos de face). 


\section{A proteção da face em uma audiência na Corte}

Em estudo anterior sobre a co-construção da impolidez na interação entre ministros do Supremo Tribunal Federal em uma audiência de julgamento, Silveira e Abritta (2015) mostraram como essa interação entre dois ministros caminhou do desacordo ao "bate-boca" em razão, principalmente, dos tipos de atos de ameaça à face empregados (ofensas de ordem profissional e de ordem moral) e dos sentidos a eles atribuídos ecologicamente pelos interagentes na ocasião. Ficou demonstrado lá também que, uma vez posto em ação um ritual de desprezo pelos desejos de face do outro, a intervenção de um terceiro ministro fez-se necessária para restabelecer o ritual de civilidade ou aquilo que um dos membros do tribunal denominou de "a liturgia da Corte". Por ora, pretendemos retomar essa mesma audiência de julgamento ${ }^{8}$, transcrita por nós, seguindo o modelo Jefferson (LODER, 2008) de parâmetros para transcrição. Porém, agora, tomamos como novo escopo verificar as estratégias de proteção da face, nos termos de Penman (1990), utilizadas pelos ministros nos momentos de conflito já estudados.

\subsection{0 recurso à deferência como forma de proteção}

Goffman (1972 [1967]) nos lembra que "assim como esperamos que um membro de qualquer grupo tenha respeito próprio, também esperamos que ele mantenha um padrão de consideração [...] com os sentimentos e a face dos outros presentes". No excerto a seguir, vejamos como e se foi coconstruído esse respeito pelos ministros. Na interação, MP é o ministro presidente da Corte e M1 o ministro com o qual MP discute. A divergência diz respeito aos critérios gerais de julgamento aplicáveis ao caso em questão:

\footnotetext{
${ }^{7}$ A expressão bate-boca encontra seu sentido já disposto nos dicionários mais conceituados da língua portuguesa, tais como, o Houssais e o Aurélio, e designa discussão agressiva, troca de palavras áspera. Optamos por não utilizar, neste caso, a palavra conflito, tida por sinônima de bateboca, por duas razões: 1. entendemos, com Goodwin (1982), que conflito é um termo guarda-chuva, incluindo aí desde um simples desacordo até um insulto e uma ameaça; 2. alinhamo-nos a Simmel (2006 [1917]), conforme dito no início deste artigo, e entendemos que conflituosas são, a priori, todas as relações inter-humanas. Importante destacar que a imprensa nacional, ao tratar do episódio analisado neste trabalho, já o tinha categorizado como um bate-boca entre ministros da Suprema Corte. Outros episódios semelhantes, ocorridos após o que aqui se destaca, vêm sendo igualmente denominados pela grande imprensa como: bate-boca. Assim, o senso comum parecenos corroborar e servir de sustentação para nossa interpretação.

8 A parte da interação sob enfoque neste texto encontra-se, publicamente, disponível para visualização no site: www.youtube.com
} 


\section{Excerto 1 "vossa excelência ME respeite"}

01 MP o tribunal pode aceitar ou rejeitar, mas não com o argumento de classe. isso faz parte

02 de impopulismo judicial.

03 M1 mas eu acho que o segundo caso prova muito bem a justeza da sua tese MAS a sua

04 tese ela deveria ter sido exposta em pratos limpos. nós deveríamos estar discutindo

05 [quem seriam os beneficiários daquilo.](bate as mãos)

06 MP [ela ela ela foi expos-] ela foi exposta em pratos limpos. Eu não sonego

07 informação. vossa excelência me respeite.

08 [vossa excelência ME respeite.] foi APONTADA em pratos limpos.=

o9 M1 [vossa excelência me respeite.]

10 =não. não [se discutiu] a lei que estav-=

No excerto acima, note que, ao ser acusado (I.03-04) por M1 de omitir informações em julgamento anterior, MP tem sua face ameaçada e toma a palavra para defendê-la. Como estratégia de salvamento da face, oferta ao outro, não as esperadas desculpas e explicações do modelo goffmaniano, mas a recusa ou rejeição ao dito, nos termos de Mclaughlin et al. (1983). A formação discursiva dessa recusa estratégica ao ato ameaçador da face faz-se valer: $1^{\circ}$ ) do uso da formulação extrema (POMERANTZ, 1986) manifesta nas negativas categóricas ao ato de omissão de informação na exposição de sua tese (I. 06): "foi exposta em pratos limpos") e à identidade de sonegador de informação que lhe fora imputada ("Eu não sonego informação", l.06-07), e $2^{\circ}$ ) da explicitação da quebra local da regra de civilidade e ao mesmo tempo a exigência de seu cumprimento, regra esta que exige deferência entre os interagentes, daí o recurso ao respeito (MP, I. 07-08: "vossa excelência me respeite. [vossa excelência ME respeite.]". Interessante notar ainda que o ato de fala de MP, I. 07-08, vem prefaciado pelo uso do pronome de tratamento "vossa excelência". Empregado por MP para se dirigir ao colega M1, hierarquicamente inferior, parece, ao mesmo tempo, prestar ao outro a deferência devida em razão do cargo e, ao mesmo tempo, cobrar-lhe o devido respeito a MP. Em se tratando de MP (ministro presidente da Corte), o ato de fala diretivo “ME RESPEITE”, pronunciado em voz alta, pode ser interpretado como uma cobrança de respeito à hierarquia do cargo por ele ocupado.

O ministro M1 (I.10), ao repetir o uso da segunda estratégia de salvamento de face usada por MP, exatamente nos mesmos termos ("[vossa excelência me respeite.]”), empregando o vocativo e o recurso ao ritual da deferência, sugere reciprocidade de tratamento com base nas regras de decoro vigentes na Corte e alegadamente sendo desrespeitadas por MP. Assim procura estabelecer um processo de salvar a face, clamando pela igualdade de direitos no tratamento interpessoal, e procura passar a imagem 
$\mathrm{EI} \square \mathrm{dA}$

Revista Eletrônica de Estudos Integrados em Discurso e Argumentação, Ilhéus, n. 17, jul./dez. 2018

do self de alguém desrespeitoso para alguém desrespeitado, o que é reforçado ao reafirmar que MP sonegou informação: "=não. não [se discutiu] a lei que estav-=“.

\subsection{O recurso à transparência da face profissional.}

O "bate-boca" entre MP e M1 ainda se agravará quando ofensas de natureza profissional vêm à tona (SILVEIRA; ABRITTA, 2015) e os efeitos desse processo sobre as faces em questão podem ser vistos a seguir:

\section{Excerto 2 "eu estava de licença"}

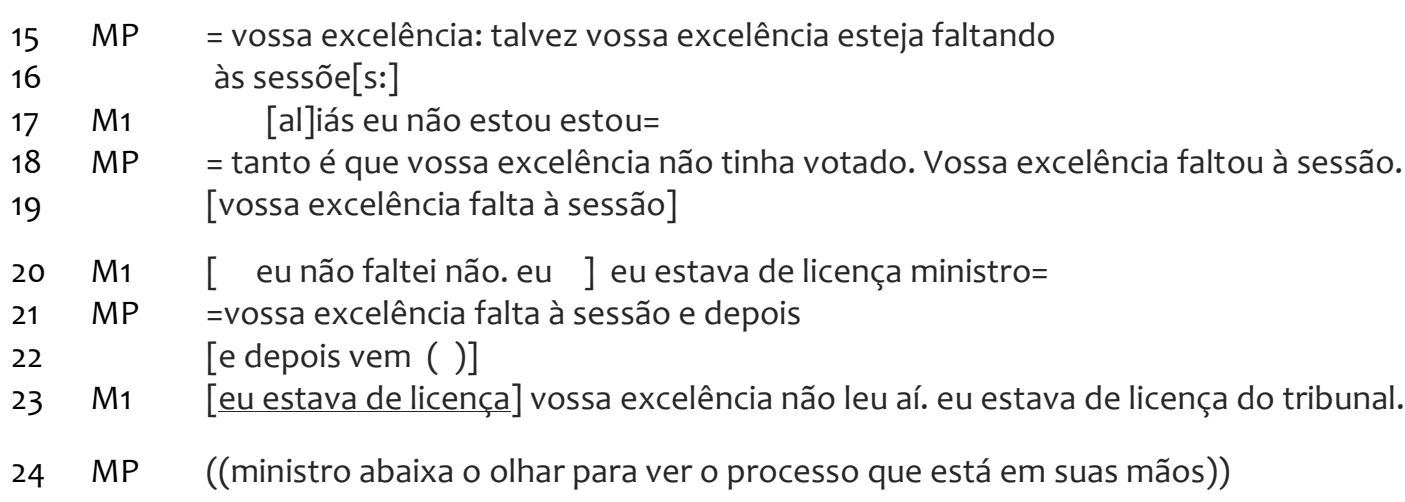

Em seus primeiros atos de fala no excerto acima, (I.15-16; I.18-19), MP acusa M1 de faltar às sessões de julgamento e, com isso, ameaça a face da competência (LIM; BOWERS, 1994) de M1, no caso, a competência profissional e coloca em questão o argumento de M1 de que MP teria sonegado informações. A defesa da face de profissional de M1 começa na linha 20 e trabalha com duas estratégias: $1^{\circ}$ ) recurso à formulação extrema através da negativa categórica da acusação - “eu não faltei não.” e $2^{\circ}$ ) no reenquadramento da definição de ausência como falta justificada, devido a estar em licença: "eu estava de licença ministro=". No entanto, note-se que MP, I.21-22, retoma a mesma acusação feita anteriormente e: desqualifica o oponente ( $\mathrm{M} 1)$, porque nega a ele o direito a questionar algo discutido em sessão em que esteve ausente, atribuindo-lhe o desconhecimento dos fatos" (SILVEIRA; ABRITTA, 2015). Na I. 23, M1, num movimento de salvamento da face, irá buscar recuperar sua face de bom profissional justificando-se novamente repetindo a estratégia do reenquadramento da ausência, agora porém, buscando apontar a evidencialidade desse fato, recorrendo ao registro da licença nos autos: "vossa excelência não leu aí. eu estava de licença do 
$\mathrm{EI} \square \mathrm{dA}$

Revista Eletrônica de Estudos Integrados em Discurso e Argumentação, Ilhéus, n. 17, jul./dez. 2018

tribunal.". Faz com isso transparecer a lisura de sua face profissional, embora não consiga afastar a questão de como poderia imputar ao outro a sonegação de informação se esteve ausente na sessão de julgamento. ${ }^{9}$

\subsection{0 recurso à face moral}

O conflito entre MP e M1, como já se poderia imaginar, não cessa, mas, ao contrário, se agrava. O bate boca ganha mais força ainda quando a moral dos oponentes é invocada como estratégia de ataque à face. Esse escalonamento do conflito pode ser visto no excerto seguinte:

\section{Excerto 3 "dar lição”}

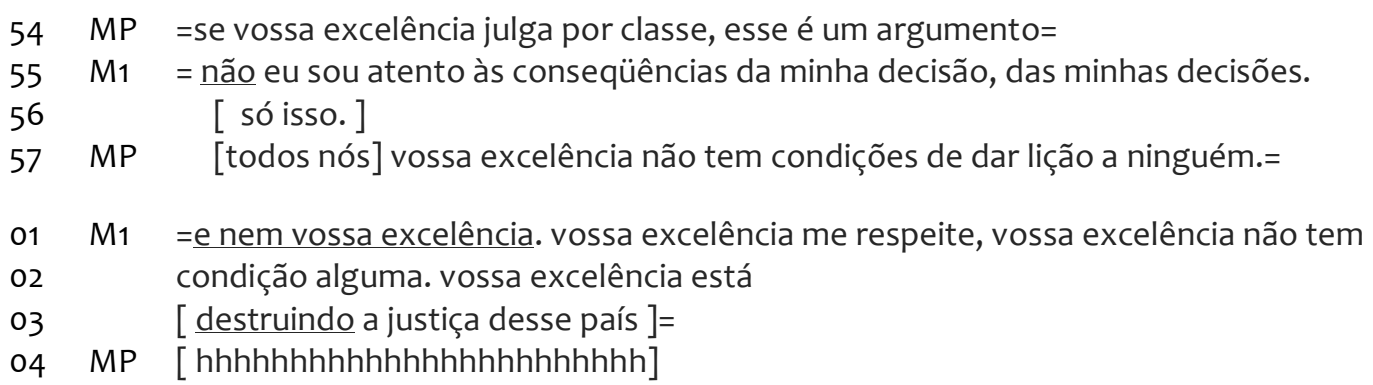

Note que, na l.54, MP parece mais uma vez atacar a face de bom profissional do colega ao questionar, por implicatura, sua imparcialidade nos critérios de julgamento, quando levanta a hipótese de que $M_{1}$ “julga por classe", ou seja, atrelado sempre a uma ideologia marxista classista. Mesmo que este ato de fala tenha vindo prefaciado pela expressão de deferência marcada, mais uma vez, pelo uso do pronome de tratamento "vossa excelência", M1 irá buscar novamente estabelecer um processo de salvamento de sua própria face (1.55-56). Primeiro, nega usar o critério de julgamento por classe e, na sequência de sua fala, procura construir uma “boa” face (O’DRISCOLL, 1996) profissional para si: mostrando-se como um julgador mais justo já que "atento às consequências da minha decisão, das minhas decisões.".

\footnotetext{
9 Importante esclarecer que, no serviço público brasileiro, as ausências atestadas, como, por exemplo, aquelas que se dão em razão de licença médica, não são computadas nas folhas de ponto dos servidores como falta. Conta-se esse dia como um dia normal de trabalho para fins de contagem de tempo de aposentadoria e também para outros benefícios a que 0 trabalhador/servidor tenha direito.
} 
A reação de MP (I.57) será a de questionar a reivindicada exclusividade dessa "boa" face de $M 1$, atribuindo-a de maneira igualitária a todos os ministros do tribunal - "[todos nós]", e ainda explicitando, com isso, o potencial ameaçador da fala de M1 às faces dos colegas. Após esse ato que procurou salvar, de uma só vez, as faces de todos os julgadores ao mesmo tempo, MP irá ainda atacar mais uma vez a face de M1. Faz isso ao questionar a moralidade de M1 para colocar-se em um patamar mais elevado que o dos demais ministros a fim de, nas palavras de MP, "dar lição".

M1(I.01-03) irá, então, buscar defender sua face negando ao outro o mesmo direito a dar lição de moral, reivindicando o respeito ao ritual da civilidade e, por último, atacando a face de MP ao acusá-lo, dizendo coisas negativas (PENMAN, 1990; SILVEIRA, 2002) sobre MP: "vossa excelência está [destruindo a justiça desse país]=".

Embora haja uma polissemia intrínseca a toda a linguagem, no contexto local, o tipo de atividade é sempre capaz de balizar os sentidos possíveis (WITTGENSTEIN, 1979). Os risos de MP (I.04), em sobreposição contínua à parte final da fala de M1, qual seja, aquela em que coloca MP como destruidor da Justiça brasileira, podem ser entendidos como uma forma de MP enquadrar a fala adjacente anterior de M1 como uma brincadeira, mas os risos também podem ser vistos como uma forma de escárnio e deboche, o que só contribui para o aumento do grau de conflito.

Ainda que o riso, enquanto fenômeno fisiológico, não envolva necessariamente o humor (ATTARDO, 1994), ele nos fornece ao menos uma "pista de contextualização para o humor" (KOTTHOFF, 2000). Desse modo, tal fenômeno pode exercer as mais variadas funções sociais na interação. Ao enquadrar uma afirmação dentro de um frame humorístico através do riso, o interlocutor pode, por exemplo, comunicar impolidez, quando o alvo da provocação a interpreta como ameaça ou ofensa, e não como uma simples brincadeira, tendo em mente que a responsabilidade pela interpretação de uma elocução como impolida é dividida entre o falante (que possui a intenção de ofender) e o ouvinte (que atribui a intenção de ofensa ao falante), (CULPEPER, 2010).

O excerto a seguir é a continuidade do anterior e nele podemos ver o emprego da estratégia de ataque à face do outro como forma de salvamento da própria face: 


\section{Excerto 4 "lição de moral"}

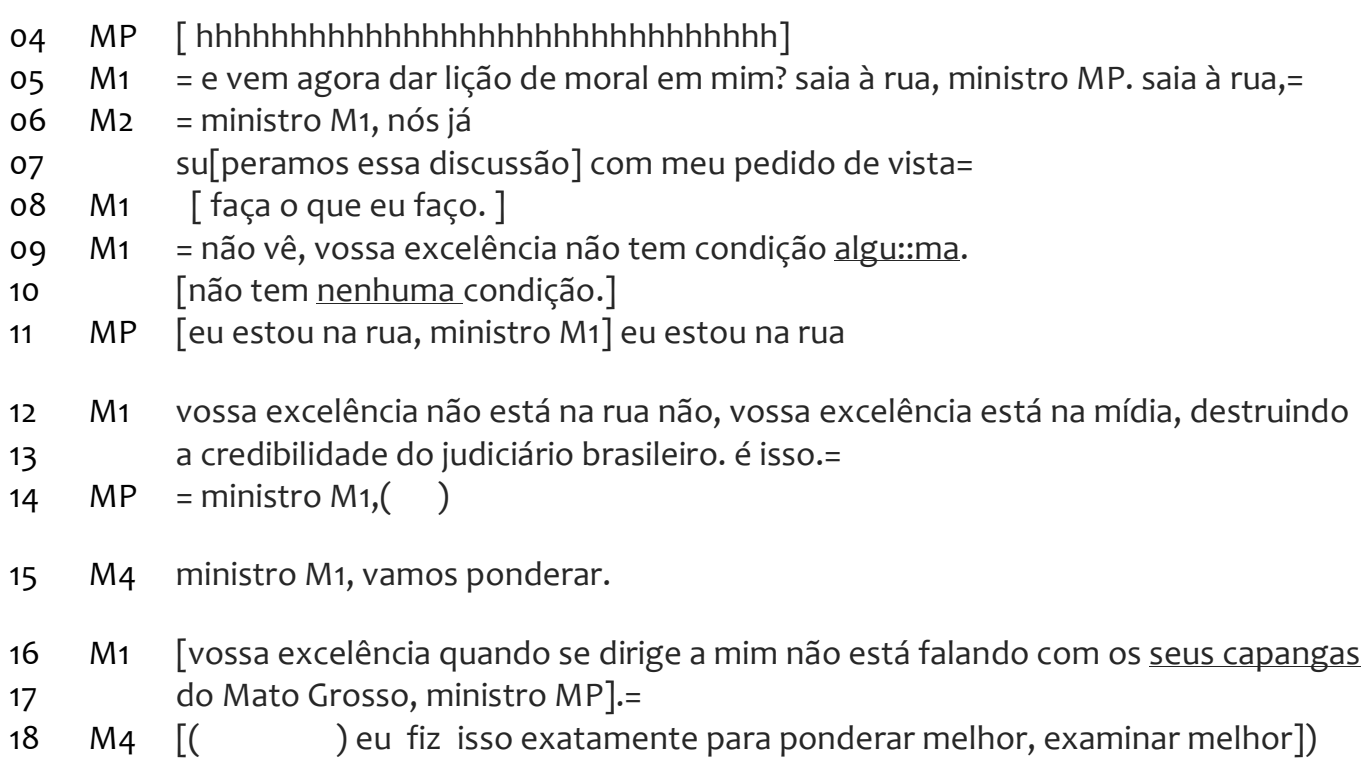

As falas de M1 (I.05; l.08-10) vêm como resposta sequencial ao riso impolido de MP. Nesses atos de fala, M1 questiona a legitimidade de MP na tentativa de dar-Ihe lição de moral. Dessa forma, M1 parece ter entendido os risos como um escárnio e, portanto, um ataque à sua face racional. Sendo assim, M1 ataca a face moral de MP apoiando-se num possível julgamento popular negativo sobre o ministro ao incitá-lo a sair às ruas.

MP busca proteger sua face questionando a veracidade dessa informação quando afirma: "[eu estou na rua, ministro M1] eu estou na rua" (I.11), com isso também ataca a face de M1 atribuindo-lhe mais uma vez a face de desinformado.

M1 contradita MP: "vossa excelência não está na rua não, vossa excelência está na mídia, destruindo a credibilidade do judiciário brasileiro. é isso.=" (I.12-13). Aqui, vê-se que, novamente, a estratégia de atacar a face do outro para proteger a própria face é usada (PENMAN, 1990). Assim, M1 nega o caráter de verdade à informação prestada por MP, qual seja, a de que estaria atento às manifestações e reivindicações da sociedade, contrapondo esse comportamento a estar preocupado em aparecer na mídia, o que, segundo M1, prestaria um desserviço à justiça brasileira.

Com o conflito aberto instaurado, parece impor-se a intervenção de um terceiro (l.15), que pede de M1 ponderação, ou seja, uma volta ao ritual litúrgico da interação local. M1, no entanto, ignora a fala de M4 e dirige-se abertamente a MP (I. 16-17), agora explicitando algo que já havíamos posto 
$\mathrm{El} \square \mathrm{dA}$

Revista Eletrônica de Estudos Integrados em Discurso e Argumentação, Ilhéus, n. 17, jul./dez. 2018

como relevante nessa interação: a questão da hierarquia local e da busca por regras igualitárias no tratamento local entre as partes. Com isso, atribui a MP uma face de alguém autoritário e discriminador, capaz de transparecer isso através do tratamento classificado como impolido por M1.

\subsection{0 recurso ao ritual da civilidade}

O altíssimo grau local de conflito pedirá a interferência de terceiros para pôr fim à discussão. E a invocação ao ritual de deferência e decoro emergirá como recurso discursivo para promover uma resolução do conflito instaurado:

\section{Excerto 5 "a liturgia do supremo"}

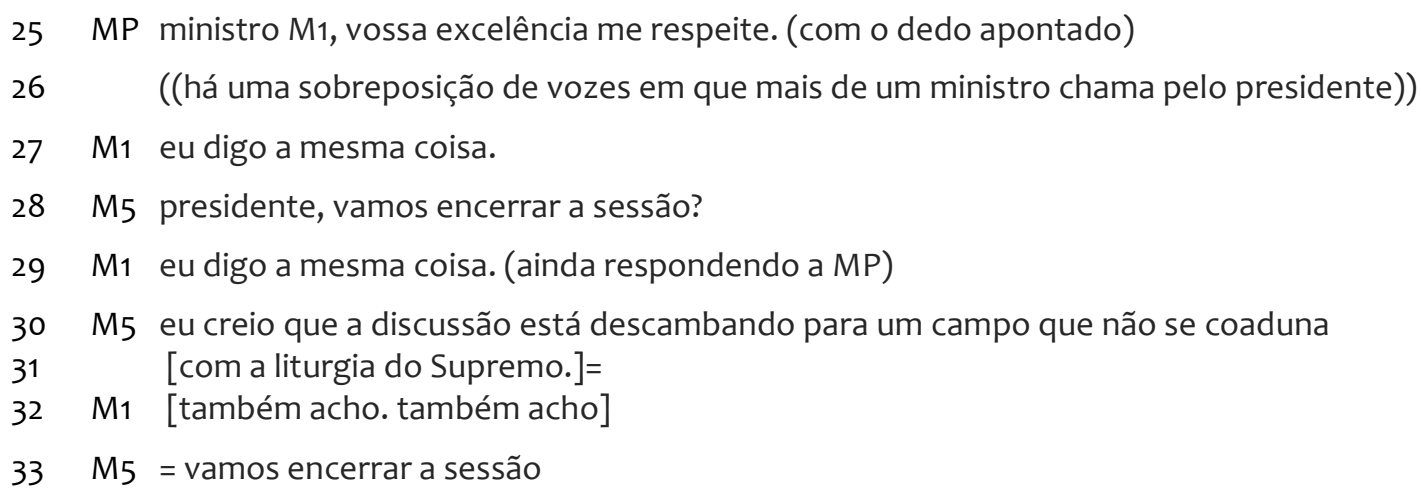

Uma vez que nenhum dos oponentes, então, recua efetivamente no processo de defacement da face por eles mesmos engendrado, um terceiro ministro intervém e, dado o alto grau de conflito a que se havia chegado, M5 pede a MP, presidente do órgão em questão, para “encerrar a sessão?" (I. 28). Na sua justificativa (l.30-31), dá a quebra do ritual local do tribunal como fator imperioso para tanto. Vale aqui lembrar Goffman (1972), para quem, a existência das regras sociais, inclusive, é claro, as de decoro, podem ser vistas exatamente nas ocasiões em que são quebradas. Pois, para o autor, nesses momentos, as pessoas costumam invocá-las para que sejam respeitadas e, assim, um dado estado de coisas, quebrado, possa ser restabelecido.

\section{Considerações Finais}

Identificamos, em nossa análise, dois principais movimentos de trabalho de face realizados por MP e M1: aumentar/ proteger a face do self e 
ameaçar/agravar a face do outro. Dentre as principais estratégias de proteção à face do self destacamos:

- O recurso à deferência como forma de proteção;

- O recurso à face profissional;

- O recurso à face moral;

- O recurso ao ritual da civilidade.

O recurso a essas estratégias emerge quando os desejos de face dos interagentes encontram-se ameaçados/agravados por informações não consistentes com as faces reivindicadas. Nos termos de Penman (1990), muitos desses recursos implicam dizer coisas positivas sobre o self e coisas negativas sobre o outro depreciando, ridicularizando, expondo inconsistências na fala do outro.

No que tange aos principais trabalhos de face de proteção aos desejos do self, pudemos identificar cinco movimentos discursivos: recusar orientação argumentativa da fala do outro; explicar defender as razões da ação; resistir de forma desafiadora; fazer exigências; negar/contestar, de forma enfática, a autoridade do outro.

Notamos ainda uma alteração importante em relação ao modelo corretivo goffmaniano. No modelo, diz-se seguir ao ato de ofensa uma oferenda em forma de desculpas ou explicações. No contexto da Corte, porém, apesar dos sucessivos movimentos de ofensa à face identificados, somente uma vez foram oferecidas explicações e nenhuma desculpa foi encontrada. O que se viu prevalecer na ecologia local foram ofertas de recusas ou rejeições ao dito nos atos ameaçadores. Apontamos que isso pode estar relacionado a um contexto de baixa hierarquia entre os interagentes; já que, muito embora estejamos falando do mais alto templo da justiça brasileira, e a interação em questão se dá entre o presidente e um ministro da Corte, os julgadores guardam entre si uma relativa igualdade de status.

Por fim, acerca da dimensão do conflito no ambiente jurídico, vê-se que, muito embora este possa ser visto como fator constitutivo das relações sociais e, portanto, não seria, a priori, negativo nem positivo; uma vez elevado ao grau de bate-boca, mesmo num contexto previamente dado como belicoso, ele, o conflito, é visto de maneira negativa e como uma quebra da "liturgia local". 


\section{Referências}

ARCHER, D. E. Verbal aggression and impoliteness. Related or synonymous? In: BOUSFIELD, D. Bousfield; LOCHER, M.A. (ed.). Impoliteness in Language. BerlIn: Mouton de Gruyter, 2008. p. 181- 207.

ARUNDALE, R. B. Constituting face in conversation: Face, facework, and interactional achievement. Journal of Pragmatics, v. 42, p. 2078-2105, 2010.

- Face as relational and interactional: A communication framework for $\overline{\text { research }}$ on face, facework and politeness. Journal of Politeness Research, v. 2, p. 193-216, 2006.

ATTARDO, S. Linguistic Theories of Humor. Berlin/New York: Mouton, 1994.

BARGIELA-CHIAPPINI, F. Face and Politeness: New (Insights) for Old (Concepts). Journal of Pragmatics, v. 35, p. 1453-1469, 2003.

; HAUGH, Mi.(eds) Face, communication and social interaction. USA: Equinox Publishing, 2009.

BOUSFIELD, D. Impoliteness in Interaction. Amsterdam/Philadelphia: John Benjamins, 2008.

BROWN, P.; LEVINSON, S. C. Politeness: Some Universals in Language Usage. Cambridge: Cambridge University Press, 1987 [1978].

CULPEPER, J. Conventionalized impoliteness formula. Journal of Pragmatics, v. 42, $n$. 12, p. 3232-3245, 2010.

GOFFMAN, E. The Interaction Order. American Sociological Review, v. 48. n. 1, p. 1-17, 1982.

. A elaboração da face: uma análise dos elementos rituais da interação social. In FIGUEIRA, S. (org.) Psicanálise e Ciências Sociais. Tradução de J. Russo. Rio, Francisco Alves, 1980, p. 76-114.

- Interactional Ritual: essays on face to face behavior. New York: Panteon. 1972 [1967]. p. 5-45.

. Relations in Public: Microstudies of the Public Order. Harmonsdsworth: Penguin, 1971.

. The presentation of self in Everyday Life. Allen Lane, Great Britain: Penguin, 1969.

GOODWIN, M. H. Process of dispute management among urban black children. American Ethnologist, n. 9, p. 76-96, 1982. Disponível em: http://www.sscnet.ucla.edu/anthro/faculty/goodwin/Processes_of_Dispute_Manage ment_Among_Urban_Black_Children.pdf. Acesso em: 29 out.2017. 
HARRÉ, R.; GILLETT, G. A mente discursiva: os avanços da ciência cognitiva. Porto Alegre: Artmed Editora, 1999.

HARRIS, S. The limits of politeness re-visited: Courtroom discourse as a case in point. In: Discursive Approaches to Politeness. Linguistic Politeness Research Group. Berlin and New York: Mouton de Gruyter, 2011.

HAUGH, M. Face and Interaction. In: BARGIELA-CHIAPPINI, F.; HAUGH, M. Face, Communication and Social Interaction. London, Oakville: Equinox, 2009, p. 1-30.

HO, D. On the concept of face. The American Journal of Sociology, vol. 8, n. 4, jan, p. $8670884,1976$.

HU, H. C. The Chinese Concepts of "Face". American Anthropologist: New Series, vol. 46, n. 1, part 1, jan-mar, 1944.

KOTTHOFF, H. Impoliteness and Conversational Joking: On Relational Politics. Folia Linguistica 30 3-4, p. 299-325, 1996.

LEECH, G. The Principles of Pragmatics. New York: Longman. 1983.

LIM, T.; BOWERS, J. W. Facework: Solidarity, Approbation, and Tact. Human communication Research. Vol. 17 (3), p.415-450, 1991.

LODER, L. L. O modelo Jefferson de transcrição: convenções e debates. In: LODER, L. L.; JUNG, N. M. Fala-em-interação social: introdução à Análise da Conversa Etnometodológica. Campinas: Mercado das Letras, 2008.

O'DRISCOLL, J. About Face: A Defence and Elaboration of Universal Dualism. Journal of Pragmatics, 25, p. 1-32, 1996.

POMERANTZ, A. Extreme case Formulations: A Way of Legitimizing Claims. Human Studies 9(2/3), p. 219-229, 1986.

PENMAN, R. Facework \& Politeness: multiple goals in courtroom discourse. Journal of Language and Social Psychology, vol.9, p. 15-38, 1990.

. Facework in Communication: Conceptual and Moral Challanges. In: TINGTOOMEY, S. (ed.). The Challenge of Facework. New York: State University of New York Press, 1994.

SILVEIRA, S. B. Estratégias de impolidez em situações de conflito. XIX Jornada de Estudos linguísticos. Fortaleza, CE: GELNE, 2002.

SILVEIRA, S. B.; ABRITTA, C. S. Trabalhos de face e os limites da impolidez no discurso jurídico. In: SILVEIRA, S. B.; ABRITTA, C. S.; VIEIRA, A. T. (org.). Linguística Aplicada em Contextos Legais. Jundiaí: Paco Editorial, 2015.

SIMMEL, G. Questões fundamentais de sociologia. Rio de Janeiro: Zahar, 2006. 


\section{$\mathrm{EI} \square \mathrm{\alpha A}$}

Revista Eletrônica de Estudos Integrados em Discurso e Argumentação, Ilhéus, n. 17, jul./dez. 2018.

. O conflito como sociação. Tradução de Mauro Guilherme Pinheiro Koury. RBSE - Revista Brasileira de Sociologia da Emoção, v. 10, n. 30, p. 568-573, 2011 [1964]. Disponível em: http://www.cchla.ufpb.br/rbse/SimmelTrad.pdf. Acesso em: 9 jun.2018.

TERKOURAFI, M. Toward a universal notion of face for a universal notion of cooperation. In: KECSKES, I.; HORN, L. (ed.). Explorations in Pragmatics: Linguistic, Cognitive and Intercultural Aspects. Berlin: Mouton de Gruyter. 2007.

TRACY, K. "Reasonable Hostility": Situation-appropriate face-attack. Journal of Politeness Research, v. 4, p. 169-191, 2008.

WATSON, R.; GASTALDO, E. Etnometodologia e Análise da Conversa. Petrópolis, RJ: Vozes, 2015.

WITTGENSTEIN, L. Investigações Filosóficas. 2. ed. São Paulo: Abril Cultural, 1979.

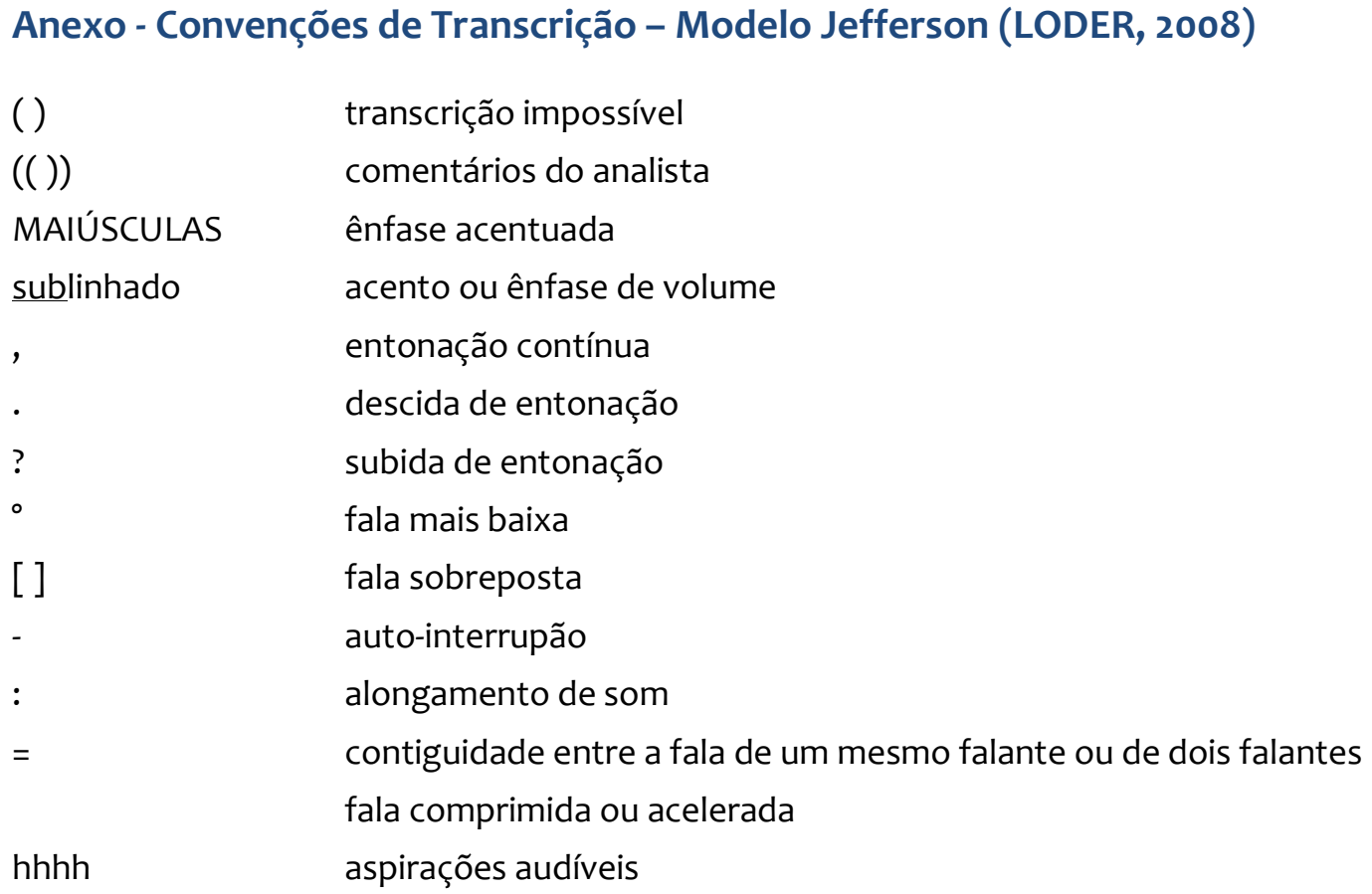

Forma de citação sugerida

ABRITTA, Carolina Scali; SILVEIRA, Sonia Bittencourt; BARRETO, Kricia Helena. Estratégias de proteção da face no cenário jurídico: um estudo de caso. EID\&A Revista Eletrônica de Estudos Integrados em Discurso e Argumentação, Ilhéus, n. 17, p. 33-50, jul./dez.2018. DOI dx.doi.org/10.17648/eidea-17-1942. 